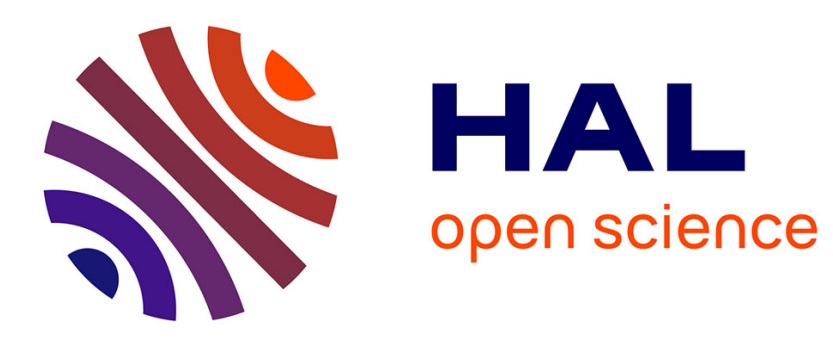

\title{
Oviposition Behavior of the Pollen Beetle (Meligethes aeneus): A Functional Study
}

Maxime Hervé, Nathan Garcia, Marie Trabalon, Anne Le Ralec, Régine

Delourme, Anne-Marie Cortesero

\section{- To cite this version:}

Maxime Hervé, Nathan Garcia, Marie Trabalon, Anne Le Ralec, Régine Delourme, et al.. Oviposition Behavior of the Pollen Beetle (Meligethes aeneus): A Functional Study. Journal of Insect Behavior, 2015, 28 (2), pp.107-119. 10.1007/s10905-015-9485-5 . hal-01117848

HAL Id: hal-01117848

https://hal-univ-rennes1.archives-ouvertes.fr/hal-01117848

Submitted on 18 Feb 2015

HAL is a multi-disciplinary open access archive for the deposit and dissemination of scientific research documents, whether they are published or not. The documents may come from teaching and research institutions in France or abroad, or from public or private research centers.
L'archive ouverte pluridisciplinaire HAL, est destinée au dépôt et à la diffusion de documents scientifiques de niveau recherche, publiés ou non, émanant des établissements d'enseignement et de recherche français ou étrangers, des laboratoires publics ou privés. 
Oviposition behavior of the pollen beetle (Meligethes aeneus): a functional study

Maxime R. Hervé ${ }^{1,2,3}$, Nathan Garcia ${ }^{3,4}$, Marie Trabalon ${ }^{5}$, Anne Le Ralec ${ }^{3,4}$, Régine Delourme $^{1}$ and Anne Marie Cortesero ${ }^{2,3}$

${ }^{1}$ INRA, UMR1349 IGEPP, F-35653 Le Rheu

${ }^{2}$ Université Rennes 1, UMR1349 IGEPP, F-35000 Rennes, France

${ }^{3}$ Université Européenne de Bretagne, France

${ }^{4}$ AGROCAMPUS OUEST, UMR1349 IGEPP, F-35000 Rennes, France

${ }^{5}$ Université Rennes 1, UMR6552 EthoS, F-35000, Rennes, France

Corresponding author:

Maxime Hervé

Tel: $+33(0) 223236158$

Email:mx.herve@gmail.com 


\begin{abstract}
The recognition by female phytophagous insects of a plant as a 'good' or 'bad' host for egg laying is based on a variety of cues (either visual, physical or chemical). Specific cues are often looked for during stereotypic oviposition behaviors, composed of several phases having their own function(s). In this study the oviposition behavior of the pollen beetle Meligethes aeneus, a pest which lays eggs in flower buds of only some brassicaceous plants, was described in detail on five oilseed rape (Brassica napus) genotypes. In parallel, setae borne by the ovipositor were characterized by scanning electron microscopy. Observations showed that the stereotypic oviposition sequence is functionally divided into three independent phases: external inspection, internal inspection and egg laying. The ovipositor plays a role in all phases by gaining information about external and internal bud parts. This role appears to be only physical since all the setae it bears are mechanoreceptors. Despite the fact that the pollen beetle is a specialist for oviposition, important variations in secondary metabolites that are typical of its host plant family (i.e. glucosinolates) on the bud did not influence clutch size. The crucial phase in the oviposition sequence seems to be the external inspection, during which poor and high-quality host plants are probably discriminated. Chemical information on bud surface is likely to be determinant in this process.
\end{abstract}

Keywords: Oilseed rape (Brassica napus); Insect pest; Plant acceptability; Behavioral sequence; Scanning Electron Microscopy 


\section{Introduction}

The classical 'preference - performance' hypothesis (e.g. Thompson 1988) predicts that female insects should be selected to lay eggs preferentially on oviposition sites that are favorable for offspring development. In phytophagous species, this hypothesis has been supported by a recent meta-analysis (Gripenberg et al. 2010). The recognition of a plant as a host or non-host, and more precisely of the quality of a host plant, is based on cues (i.e. plant traits) used by females. These can be either chemical and/or visual, acting at distance (e.g. volatile compounds, size or architecture) and/or at contact (e.g. primary and secondary metabolites inside and on surface of plant tissues, trichome density, tissue thickness or toughness).

In many insect species, females show a stereotypic oviposition behavior (e.g. the cabbage root fly Delia radicum (Städler and Schöni 1990), the mustard leaf beetle Phaedon cochleariae (Müller and Rosenberger 2006) or the cabbage seedpod weevil Ceutorhynchus obstrictus (Ulmer and Dosdall 2006)). Such behavioral sequence is often divided into several phases, each of them having one or several precise function(s). Specific host cues are detected during these phases, by means of sensory organs such as mechano- or chemoreceptors borne by antennae, tarsi or the ovipositor. Describing stereotypic oviposition behaviors, deciphering their function(s) and characterizing sensory organs that are used by females is the first step before identifying specific cues used by females to evaluate plant quality.

The pollen beetle (Meligethes aeneus F.; Coleoptera: Nitidulidae) is one of the major insect pests of oilseed rape (Brassica napus L.; Brassicaceae) (OSR) crops. Females lay eggs only on brassicaceous plants (Ekbom and Borg 1996; Free and Williams 1978). Adults colonize OSR fields after their winter diapause, when plants are at the bud stage. They destroy flower buds to reach the pollen inside, from which they feed. This destruction sometimes leads to 
important yield losses (Nilsson 1987). Mating occurs on the plant and females oviposit inside buds, after having made a small hole at its base. Reproduction goes on until death of the individuals, in summer. Buds are not destroyed during oviposition and usually continue their normal development. Larvae hatch inside the bud and feed from the pollen contained in anthers during their first instar. Transition to the second (and last) instar occurs approximately as the flower opens. Second-instar larvae move from one flower to another, still feeding on pollen. They finally drop from the plant at the end of their development and pupate in the soil (Williams 2010).

Not all brassicaceous plants are accepted for oviposition by females even when they are attractive at distance (Cook et al. 2004; Kaasik et al. 2014a, 2014b; Veromann et al. 2012). Cues present on the buds and acting upon contact play a key role in determining oviposition. White mustard Sinapis alba is, for example, especially known to be a low-quality host for the pollen beetle (Ekbom 1998; Ekbom and Borg 1996; Hopkins and Ekbom 1996, 1999; Hopkins et al. 1998). Borg and Ekbom (1996) characterized for the first time the oviposition behavior of pollen beetle females and proved that $S$. alba is of inferior acceptability (in the strict sense of Singer (2000)) compared to Brassica spp. They showed that the flower bud is inspected in a stereotypic sequence before oviposition, and that this inspection can lead to females stopping the sequence and leaving the plant. Although contact cues appear essential in determining plant acceptability, these authors were not able to identify the cues females use to make their decision.

The aims of this study were (i) to describe in more detail the oviposition behavior of the pollen beetle, (ii) to give a functional interpretation of the different steps of the behavioral sequence, and (iii) to identify the critical step(s) of this sequence determining the acceptance of the plant. For this purpose, five OSR genotypes for which the biochemical composition of buds is known (Hervé et al. 2014a) were compared in a no-choice experiment, as precisely as 
possible. As the ovipositor is known to bear setae in its distal part in the Meligethinae subfamily (Audisio et al. 2009), morphology of these setae was also characterized by scanning electron microscopy (SEM) to understand their function.

\section{Material and methods}

\section{Plants}

All genotypes used in this study were lines from the INRA OSR collection (BraCySol Center for Genetic Resources, INRA, Le Rheu, France). Both winter (genotypes 'Darmor', 'Express' and 'Mar') and spring (genotypes 'Liho' and 'Yudal') OSR genotypes were used. Plants were produced in controlled conditions as described in Hervé et al. (2014a) and used at BBCH stage 55-57 (Lancashire et al. 1991), i.e. the 'green bud stage'. To keep the interaction natural, entire intact plants were used.

\section{Insects}

Overwintered pollen beetle females were collected from an unsprayed winter OSR crop near Le Rheu (Brittany, France), in April-May. Females were identified by observing mating behavior. Experiments took place within $3 \mathrm{~h}$ after field collection.

\section{Oviposition behavior characterization}

One female was placed on the main inflorescence of an intact OSR plant, in a plastic pot (diameter $6.5 \mathrm{~cm}$, height $9 \mathrm{~cm}$ ) isolating this inflorescence from the rest of the plant. As described by Borg and Ekbom (1996), the beginning of the oviposition sequence is discernible when, after walking on several buds, a female walks circuitously on the same bud. Observations were carried out by constantly following the female with a hand magnifier (x 5), 
recording the sequence and the duration of each behavior with a handheld recorder, and transcribing it later with the interface SequenceR (Hervé 2013). Based on the previous characterization of Borg and Ekbom (1996) and our preliminary observations, six behaviors were considered (Table 1). After the end of the sequence, the bud in which the female oviposited was measured and dissected to count the number of eggs laid. A different plant was used for each female. Thirty different individuals were recorded per OSR genotype. Replicates were conducted randomly through time (total study period: about one month) and experiments took place at $20^{\circ} \mathrm{C}$.

\section{Scanning electron microscopy of the ovipositor}

About 40 ovipositors were dissected, dehydrated by successive alcohol-bath (70 \%, $80 \%, 90$ $\%, 96 \%$ and $100 \%$ ), critical-point dried and coated with gold-paladium. Observations were then performed with a JSM-7100F (Jeol) microscope.

\section{Statistical analysis}

All statistical analyses were performed using R software (R Core Team 2013). The proportion of females completing their oviposition sequence was compared among genotypes using a likelihood ratio test on a Generalized Linear Model (GLM) (distribution: binomial, link function: logit). Only females that completed their sequence were included in subsequent analyses. Number of eggs laid was analyzed using a likelihood ratio test on a GLM (distribution: Poisson, link function: $\log$ ) taking into account OSR genotype, size of the bud in which oviposition took place and duration of each behavior. ANOVAs were used to compare genotypes for the size of the bud in which the female oviposited, the duration of each behavior (durations of 'Walking with ovipositor' and 'Resting' had to be log-transformed for a better model fit) and the total duration of the sequence. When needed, pairwise comparisons 
of Least Squares Means were performed using the function '1smeans' (package '1smeans' (Lenth 2013)) and the False Discovery Rate (FDR) correction for $P$-values (Benjamini and Hochberg 1995). Pearson's correlation tests were used to assess the relationship between duration of all pairs of behaviors. The $P$-value of each test was adjusted with the FDR correction.

\section{Results}

\section{Oviposition behavior characterization}

The mean length $( \pm$ SE) of the bud in which pollen beetle females laid eggs was $4.0( \pm 0.07)$ $\mathrm{mm}$. Although the size of all buds forming an OSR raceme are quite variable, ranging between less than $1 \mathrm{~mm}$ and 7-8 $\mathrm{mm}$ long, only a narrow size range was used by females (90 $\%$ of chosen buds had a length between 3 and $5.5 \mathrm{~mm}$ ). No difference was observed among the five OSR genotypes for the length of the chosen bud $\left(\mathrm{F}_{4,128}=0.80, P=0.525\right)$. The observed sequences were consistent with the description of Borg and Ekbom (1996), but we recorded finer details during two particular steps. Firstly, Borg and Ekbom (1996) described a behavior of "walking with the abdomen touching the bud surface". Our observations showed that during this step, the abdomen is very close to the bud surface but does not touch it, and the ovipositor is partly extruded, tapping for a few seconds with its distal end on the bud surface. Secondly, Borg and Ekbom (1996) described a behavior consisting of "placing the abdomen over the bite hole". Our observations showed that the abdomen is not only placed over the hole, but that the ovipositor is fully extruded and inserted inside the hole, tapping on bud organs we were not able to identify. Finally, we add that antennae were constantly used to tap the bud surface throughout the 'Walking' and 'Walking with ovipositor' behaviors. 
No difference was found among OSR genotypes for the duration of 'Walking', 'Walking with ovipositor', 'Resting' and 'Oviposition' (Table 2). On the contrary, the mean duration of 'Biting' and 'Ovipositor inside hole' was significantly longer in genotypes 'Darmor' and 'Mar' compared to 'Express', 'Liho' and 'Yudal'. Consequently, the mean total time of the sequence was greater in 'Darmor' and 'Mar' than in the three other genotypes. Pairwise correlations between durations of each behavior (Table 3) revealed that all durations were independent, except for two pairs. First, the time spent walking was highly positively correlated to the time spent walking with the ovipositor tapping on the bud surface. Secondly, the time spent biting the perianth was highly positively correlated to the time spent with the ovipositor tapping inside the bud.

A high proportion of females completed their oviposition sequence (overall proportion [95\% CI]: $0.89[0.82-0.93])$. This proportion was not statistically different among the OSR genotypes (Table 2). Altogether, 17 females left the bud before laying eggs. Six left it before biting any hole, after a mean time $( \pm$ SE) of $561.2( \pm 94.0)$ s $(26.6 \%$ of the mean total time of completed sequences). The other eleven females left the bud after at least starting biting, after a mean time of $1,250.4( \pm 269.2)$ s $(59.4 \%$ of the mean total time of completed sequences $)$. Between one-six eggs were laid, with a mean $( \pm$ SE) of $2.88( \pm 0.11)$. The number of eggs laid was not influenced by any variable except the duration of the 'Oviposition' behavior (Genotype: $\chi^{2}=3.07, d f=4, P=0.547$; Size of the bud in which eggs were laid: $\chi^{2}=0.02, d f$ $=1, P=0.890$; 'Walking': $\chi^{2}=0.001, d f=1, P=0.971$; 'Walking with abdomen' $: \chi^{2}=0.88$, $d f=1, P=0.349 ;$ 'Resting' $: \chi^{2}=0.03, d f=1, P=0.866$; 'Biting' $: \chi^{2}=0.24, d f=1, P=0.625$; 'Abdomen over hole': $\chi^{2}=0.50, d f=1, P=0.481$; 'Oviposition': $\chi^{2}=4.37, d f=1, P=$ 0.037). The more time a female spent laying eggs, the more eggs were laid. 
Scanning electron microscopy of the ovipositor

Sixteen setae were found on each half of the ovipositor. They were located at the end of the gonostyloid (i.e. the distal end of the gonocoxites), for one part on the gonostyloid themselves and for the other part on two cylindrical styli (Fig. 1b, c). Two types of sensilla were observed: long trichoid sensilla (between 10-15 $\mu \mathrm{m}$ long; Fig. 1d) and short basiconic sensilla (2-3 $\mu \mathrm{m}$ long; Fig. 1e, f). Both types were strictly aporous.

\section{Discussion}

\section{Functional organization of the oviposition sequence}

Borg and Ekbom (1996) made the first, broad description of the oviposition behavior of the pollen beetle. Based on our results on the correlation and the transitional frequencies between behaviors, we were able to go further and draw a general functional view of the oviposition sequence of this species (Fig. 2). This sequence is divided into three independent steps: the first comprising alternate walking and walking with the ovipositor tapping on the bud surface. This probably represents 'external inspection' of the bud. If the female did not leave the bud during this first step, the second step started. This comprised alternate biting of the oviposition hole and, after a U-turn, placing the ovipositor inside this hole and tapping on internal organs of the bud. We called this phase 'internal inspection'. Finally, if the female did not leave the bud during the second step, the third and final step (consisting of laying eggs) started.

\section{External inspection}

It is very likely that external inspection of the bud surface has several functions. Pollen beetle females oviposited only in a narrow bud size range, which supports previous results (Ekbom 
and Borg 1996; Ferguson et al. 2014; Nilsson 1989). This bud selection is considered as an adaptive compromise between the protection of larvae against natural enemies until bud opening, and the amount of food (i.e. pollen) available for these larvae during the first part of their development (Ekbom and Borg 1996). The external inspection, as it is the first step of the oviposition sequence, probably plays a crucial role in evaluating the size of the bud. The process by which the female assesses this size is unknown, but it might be based on a comparison with its own size.

The majority of females oviposited on the five studied OSR genotypes, confirming that OSR is a host species of high acceptability. Borg and Ekbom (1996) showed that during the external inspection, $S$. alba, a known low-quality host plant species for the pollen beetle (Ekbom 1998; Ekbom and Borg 1996; Hopkins and Ekbom 1996, 1999) was systematically rejected after a very short walk on the bud surface. A second function of this phase of the oviposition sequence could hence be to discriminate between poor and high-quality host plants. Cues that are used by the female to perform such discrimination are likely to be multiple. Indeed, phytophagous insects and plant surfaces interact in a complex manner, as both physical and chemical parameters can influence insect behavior (reviewed in Müller and Riederer (2005)). However, as the pollen beetle oviposits only on certain brassicaceous plant species, it is likely that chemical cues (e.g. surface metabolites), which are more specific than physical ones (e.g. trichome density), are of primary importance. Interestingly, we observed that female's antennae are constantly used to tap the bud surface throughout the external inspection. This suggests that surface compounds are sampled during this phase of the oviposition sequence.

Our results revealed that the female's ovipositor plays an active role in the external inspection, by tapping on the bud surface. This organ is known to bear sensilla at its distal end (Audisio et al. 2009), although their nature remains unknown. Our observations showed that 
all of them are totally aporous, clearly indicating that they have a sole, mechanosensory role (Chapman 2013). The function of the behavior 'Walking with ovipositor' is probably therefore to get physical information from the bud. It may either be the toughness or the thickness of the perianth which has to be pierced to bite the oviposition hole.

\section{Internal inspection}

The internal inspection consists of alternating biting of the oviposition hole and tapping inside the bud with the ovipositor. During biting, it is possible that the female would be influenced by cues from the perianth, which could either be physical or chemical. Although often neglected, plant toughness can negatively influence chewing insects by reducing consumption rate (Clissold et al. 2009). On the other hand, mouth parts of insects are a 'hot spot' of chemosensory receptors (Chapman 2013) and the pollen beetle is not an exception (Błażejewicz-Zawadziska and Błażejewski 2002). Interestingly, clear differences appeared among OSR genotypes, dividing them into two groups. The biochemical composition of the perianth of all of these genotypes has previously been characterized by Hervé et al. (2014a) and showed two clear results. Firstly, 'Yudal' is much more concentrated in total glucosinolates - secondary metabolites typical of a few plant families including Brassicaceae (Fahey et al. 2001) - than the other genotypes (in descending order and relatively to 'Yudal': 'Express' 0.22, 'Darmor' 0.11, 'Liho' 0.04 and 'Mar' 0.04). Glucosinolate profiles are similar; differences are essentially quantitative. Biting duration being equivalent on 'Yudal', 'Express' and 'Liho', this suggests that there is no link between glucosinolate content of the perianth and biting duration (Fig. 3a). Moreover, the number of eggs laid was not different among genotypes, which also indicates the absence of link between glucosinolate content of the perianth and clutch size (Fig. 3b). These results confirm those of Hervé et al. (2014b) that an important increase in glucosinolate content (maximum - minimum ratio: 23.4) does not 
further stimulate oviposition of the pollen beetle. Such a pattern was previously reported for another insect specialized on brassicaceous plants, the cabbage seedpod weevil Ceutorhynchus obstrictus (Ulmer and Dosdall 2006). This conclusion is rather unexpected, as increased amounts of glucosinolates generally stimulate feeding and oviposition of phytophagous insects specialized on brassicaceous plants (reviewed in Hopkins et al. 2009). It has to be noted that since we did not use glucosinolate-free plants, it cannot be concluded that these compounds do not stimulate oviposition at all. Secondly, Hervé et al. (2014a) showed a gradient of feeding stimulation among the same five genotypes: 'Express' is the most stimulant, 'Liho' the least and the three others are intermediate. Again, biting duration does not seem to be linked with perianth biochemistry. All of these results suggest that biting duration could be independent of the biochemical composition of the perianth and is possibly influenced only by its structural characteristics. Finally, since no difference in the acceptability or in the number of eggs laid has been observed among the five OSR genotypes, it seems that oviposition is not determined by cues present in the perianth of this host plant. Further studies on a greater number of genotypes are needed to confirm this hypothesis. During the internal inspection, pollen beetle females tap inside the flower bud with their ovipositor. In a study comparing two OSR genotypes producing male-fertile or male-sterile flowers (Cook et al. 2004), pollen beetle females made the same number of oviposition holes on buds from the two types of plants. However, oviposition took place more often on malefertile plants (i.e. the likelihood of laying eggs after having making a hole was greater in pollen-containing buds). These results, combined with our observations on the mechanosensory function of ovipositor's sensilla, suggest that the behavior 'Ovipositor inside hole' is likely to be no more than a simple assessment of the presence (and possibly the size) of anthers. 
Finally, it seems that during the second phase of the oviposition sequence of the pollen beetle, chemical (i.e. specific) information provided by the bud does not play an important role. It suggests that this phase is not decisive in the assessment of host quality. This is concurrent with the results of Borg and Ekbom (1996) who found that even on the low-quality host $S$. alba, once females started this phase they did not stop the sequence until its end. In our study, it is likely that the few interruptions that occurred after females started biting their oviposition hole were accidental and not purposeful. Some disturbance in our experimental conditions may have occurred.

\section{Oviposition}

The third and last phase of the oviposition sequence consists of laying eggs. We found no difference among OSR genotypes in terms of number of eggs laid. Borg and Ekbom (1996) showed that for females completing their sequence, there was no difference among host species differing in their quality. In the same manner, Cook et al. (2004) showed that for females having oviposited, the same number of eggs was laid in male-fertile and male-sterile buds. These results suggest that clutch size of the pollen beetle is not influenced by immediate cues obtained during the oviposition sequence. The daily egg load of individual pollen beetle females has previously been shown to be between one and five eggs (Ekbom and Ferdinand 2003; Ferguson et al. 2014; Hopkins and Ekbom 1996). Our results suggest that, if a host plant is accepted, all available mature eggs are laid.

\section{Conclusion}

Our observations have resulted in a more detailed characterization of the behavioral sequence of oviposition in pollen beetle, and highlighted the importance of females' ovipositor in gaining information from the oviposition site. Combined with results of previous studies, we 
were able to draw a functional scheme of the oviposition sequence, divided into three phases. Oviposition starts with an external inspection of the flower bud, in which the acceptability of the plant is assessed. This assessment is likely to be influenced mainly by chemical information, i.e. surface metabolites. This is likely to be the critical step, discriminating low and high-quality host plants. The second phase is an internal inspection of the bud, probably essentially influenced by structural parameters of the perianth and during which the presence (and possibly the size) of anthers (i.e. food for larval development) is assessed. Finally, the third phase consists of laying probably all the mature eggs the female is carrying.

\section{Acknowledgments}

We are very grateful to Jo Le Lannic, Francis Gouttefangeas, Loïc Joanny and Maryline Guilloux-Viry for their help with the SEM and to the UMR IGEPP glasshouse team for taking care of the plants used in this study. Maxime Hervé was supported by a CJS grant from the French National Institute of Agronomical Research.

\section{References}

Audisio P, Cline AR, De Biase A, Antonini G, Mancini E, Trizzino M, Costantini L, Strika S, Lamanna F, Cerretti P (2009) Preliminary re-examination of genus-level taxonomy of the pollen beetle subfamily Meligethinae (Coleoptera: Nitidulidae). Acta Entomol Musei Nat Pragae 49(2): 341-504

Benjamini Y, Hochberg Y (1995) Controlling the false discovery rate: a practical and powerful approach to multiple testing. J R Stat Soc B 57: 289-300 
Błażejewicz-Zawadziska M, Błażejewski F (2002) Sensory organs of mouth parts of selected species of the genus Meligethes Stephens (Coleoptera: Nitidulidae). Wiadomości Entomologiczne 21(3): 137-154

Borg A, Ekbom B (1996) Characteristics of oviposition behaviour of the pollen beetle, Meligethes aeneus on four different host plants. Entomol Expl Appl 81: 277-284

Chapman RF (2013) Mechanoreception. In: Simpson SJ, Douglas AE (eds) The Insects: structure and function, 5th edn. Cambridge University Press, New York, US, pp. 738-770

Clissold FJ, Sanson GD, Read J, Simpson SJ (2009) Gross vs. net income : how plant toughness affects performance of an insect herbivore. Ecology 90(12): 3393-3405

Cook SM, Murray DA, Williams IH (2004) Do pollen beetles need pollen? The effect of pollen on oviposition, survival, and development of a flower-feeding herbivore. Ecol Entomol 29: 164-173

Ekbom B (1998) Clutch size and larval performance of pollen beetles on different host plants. Oikos 83(1): 56-64

Ekbom B, Borg A (1996) Pollen beetle (Meligethes aeneus) oviposition and feeding preference on different host plant species. Entomol Expl Appl 78: 291-299

Ekbom B, Ferdinand V (2003) Field oviposition rates and egg load dynamics of pollen beetles (Meligethes aeneus Fab.) (Coleoptera: Nitidulidae). Agr Forest Entomol 5: 247-252

Fahey JW, Zalcmann AT, Talalay P (2001) The chemical diversity and distribution of glucosinolates and isothiocyanates among plants. Phytochemistry 56: 5-51

Ferguson AW, Nevard LM, Clark SJ, Cook SM (2014) Activity-temperature relationships in Meligethes aeneus: implications for pest management. Pest Manag Sci

DOI: $10.1002 / p s .3860$ 
Free JB, Williams IH (1978) The responses of the pollen beetle, Meligethes aeneus, and the seed weevil, Ceutorhynchus assimilis, to oil-seed rape, Brassica napus, and other plants. J Appl Ecol 15(3): 761-774

Gripenberg S, Mayhew PJ, Parnell M, Roslin T (2010) A meta-analysis of preferenceperformance relationships in phytophagous insects. Ecol Lett 13: 383-393

Hervé M (2013) SequenceR : une interface d'encodage de séquences comportementales. http://www.maximeherve.com/r-statistiques/sequencer

Hervé MR, Delourme R, Gravot A, Marnet N, Berardocco S, Cortesero AM (2014a) Manipulating feeding stimulation to protect crops against insect pests? J Chem Ecol. doi: 10.1007/s10886-014-0517-y

Hervé MR, Delourme R, Leclair M, Marnet N, Cortesero AM (2014b) How oilseed rape (Brassica napus) genotype influences pollen beetle (Meligethes aeneus) oviposition. Arthropod Plant Interact 8: 383-392

Hopkins RJ, Ekbom B (1996) Low oviposition stimuli reduce egg production in the pollen beetle Meligethes aeneus. Physiol Entomol 21: 118-122

Hopkins RJ, Ekbom B (1999) The pollen beetle, Meligethes aeneus, changes egg production rate to match host quality. Oecologia 120: 274-278

Hopkins RJ, Ekbom B, Henkow L (1998) Glucosinolate content and susceptibility for insect attack of three populations of Sinapis alba. J Chem Ecol 24(7): 1203-1216

Hopkins RJ, van Dam NM, van Loon JJA (2009) Role of glucosinolates in insect-plant relationships and multitrophic interactions. Annu Rev Entomol 54: 57-83

Kaasik R, Kovács G, Toome M, Metspalu L, Veromann E (2014a) The relative attractiveness of Brassica napus, B. rapa, B. juncea and Sinapis alba to pollen beetles. BioControl 59: $19-28$ 
Kaasik R, Kovács G, Kaart T, Metspalu L, Williams IH, Veromann E (2014b) Meligethes aeneus oviposition preferences, larval parasitism rate and species composition of parasitoids on Brassica nigra, Raphanus sativus and Eruca sativa compared with on Brassica napus. Biol Control 69: 65-71

Lancashire PD, Bleiholder H, Vandenboom T, Langeluddeke P, Strauss R, Weber E, Witzenberger A (1991) A uniform decimal code for growth-stages of crops and weeds. Ann Appl Biol 119: 561-601

Lenth RV (2013) lsmeans: Least-squares means. R package version 1.10-4. http://CRAN.Rproject.org/package=lsmeans

Müller C, Riederer M (2005) Plant surface properties in chemical ecology. J Chem Ecol 31(11): 2621-2651

Müller C, Rosenberger C (2006) Different oviposition behaviour in Chrysomelid beetles: characterization of the interface between oviposition secretion and the plant surface. Arthropod Struct Dev 35: 197-205

Nilsson C (1987) Yield losses in summer rape caused by pollen beetles (Meligethes spp.). Swed J Agr Res 17: 105-111

Nilsson C (1989) The pollen beetle (M. aeneus F.) in winter and spring rape at Alnarp 19761978. II. Oviposition. Växtskyddsnotiser 52(6): 139-144

R Core Team (2013) R: A language and environment for statistical computing. R Foundation for Statistical Computing, Vienna, Austria. URL http://www.R-project.org/

Singer MC (2000) Reducing ambiguity in describing plant-insect interactions: "preference", “acceptability" and "electivity". Ecol Lett 3: 159-162

Städler E, Schöni R (1990) Oviposition behavior of the cabbage root fly, Delia radicum (L.), influenced by host plant extracts. J Insect Behav 3(2): 195-209 
Thompson JN (1988) Evolutionary ecology of the relationship between oviposition preference and performance of offspring in phytophagous insects. Entomol Expl Appl 47: 3-14

Ulmer BJ, Dosdall LM (2006) Glucosinolate profile and oviposition behavior in relation to the susceptibilities of Brassicaceae to the cabbage seedpod weevil. Entomol Expl Appl 121: $203-213$

Veromann E, Metspalu L, Williams IH, Hiiesaar K, Mand M, Kaasik R, Kovács G, Jogar K, Svilponis E, Kivimagi I, Ploomi A, Luik A (2012) Relative attractiveness of Brassica napus, Brassica nigra, Eruca sativa and Raphanus sativus for pollen beetle (Meligethes aeneus) and their potential for use in trap cropping. Arthropod Plant Interact. doi: $10.1007 / \mathrm{s} 11829-012-9191-6$

Williams IH (2010) The major insect pests of oilseed rape in Europe and their management: an overview. In: Williams IH (ed) Biocontrol-based integrated management of oilseed rape pests. Springer, London, UK, pp. 1-43 
Table 1. Behaviors used to characterize the oviposition sequence of M. aeneus

\section{Behavior}

\section{Walking}

Walking with ovipositor

Resting

Biting

Ovipositor inside hole

Oviposition

\section{Description}

All locomotion except for "Walking with ovipositor"

Walking with ovipositor tapping on the bud surface

No locomotion

Female stays at the same place and chews on the bud; once a hole is initiated all biting behavior occurs at the same location

Female stays at the same place, inserts her ovipositor inside the hole

bitten and taps on internal bud organs. The female is wiggling and antennae are constantly agitated

Ovipositor is inserted into the hole and egg(s) laid. The female is completely immobile, including antennae 
Table 2. Results of (i) ANOVAs comparing durations of each behavior and total oviposition sequence of M. aeneus on oilseed rape; (ii) likelihood ratio tests comparing number of eggs and number of females having completed their oviposition sequence. Mean (SE) values are given. For significant ANOVAs, different letters show statistically different means. $P$-values less than $\alpha=0.05$ are represented in bold

\begin{tabular}{|c|c|c|c|c|c|c|c|}
\hline & & & \multicolumn{5}{|c|}{ Genotype } \\
\hline & $\mathbf{F}_{4,128}$ & $P$ & Darmor & Express & Liho & Mar & Yudal \\
\hline \multicolumn{8}{|l|}{ Behavior duration (s) } \\
\hline Walking & 0.844 & 0.500 & $456.2(50.4)$ & $363.5(46.8)$ & $369.9(39.5)$ & $382.1(54.3)$ & $447.1(50.7)$ \\
\hline Walking with ovipositor & 1.440 & 0.225 & $39.1(9.3)$ & $22.5(5.0)$ & $37.1(3.9)$ & $42.3(11.9)$ & $33.7(5.4)$ \\
\hline Resting & 1.503 & 0.205 & $22.3(7.1)$ & $8.4(3.9)$ & $17.9(5.3)$ & $21.8(8.7)$ & $26.2(12.4)$ \\
\hline Biting & 8.780 & $<0.001$ & $1256.1(128.2) \mathrm{a}$ & $705.8(83.9) b$ & $629.0(84.3) \mathrm{b}$ & $1181.9(126.6) \mathrm{a}$ & $671.1(83.8) \mathrm{b}$ \\
\hline Ovipositor inside hole & 5.636 & $<0.001$ & $541.2(73.7) \mathrm{a}$ & $285.0(51.0) \mathrm{b}$ & $266.1(34.0) b$ & $461.4(59.6) \mathrm{a}$ & $280.1(42.4) \mathrm{b}$ \\
\hline Oviposition & 1.035 & 0.392 & $425.7(40.4)$ & $452.6(47.6)$ & $366.6(41.8)$ & $358.2(46.7)$ & $461.4(57.7)$ \\
\hline \multirow[t]{2}{*}{ Total sequence (s) } & 7.516 & $<0.001$ & $2741.2(200.1) \mathrm{a}$ & $1837.6(144.1) b$ & $1686.7(137.1) b$ & $2450.3(163.1) \mathrm{a}$ & $1919.7(167.6) \mathrm{b}$ \\
\hline & $\chi_{4}^{2}$ & $P$ & & & & & \\
\hline Number of eggs & 3.066 & 0.547 & $3.1(0.2)$ & $2.9(0.3)$ & $3.1(0.3)$ & $2.4(0.2)$ & $2.9(0.2)$ \\
\hline
\end{tabular}


Proportion of females completing sequence
4.183

0.382

$25 / 30$

$27 / 30$

29/30

$25 / 30$

$27 / 30$ 
Table 3. Pearson's correlation coefficients between durations of behaviors of the oviposition sequence of $M$. aeneus on oilseed rape $(d f=131$ in each case)

\begin{tabular}{|c|c|c|c|c|c|}
\hline & $\begin{array}{c}\text { Walking with } \\
\text { ovipositor }\end{array}$ & Resting & Biting & $\begin{array}{l}\text { Ovipositor } \\
\text { inside hole }\end{array}$ & Oviposition \\
\hline Walking & $0.598 * * *$ & 0.052 & -0.012 & 0.149 & 0.011 \\
\hline Walking with ovipositor & - & 0.044 & 0.021 & 0.107 & -0.032 \\
\hline Resting & - & - & 0.066 & 0.044 & -0.071 \\
\hline Biting & - & - & - & $0.700 * * *$ & 0.039 \\
\hline Ovipositor inside hole & - & - & - & - & 0.043 \\
\hline
\end{tabular}

No symbol: $\mathrm{P}>0.05 ; * * * \mathrm{P}<0.001$ 

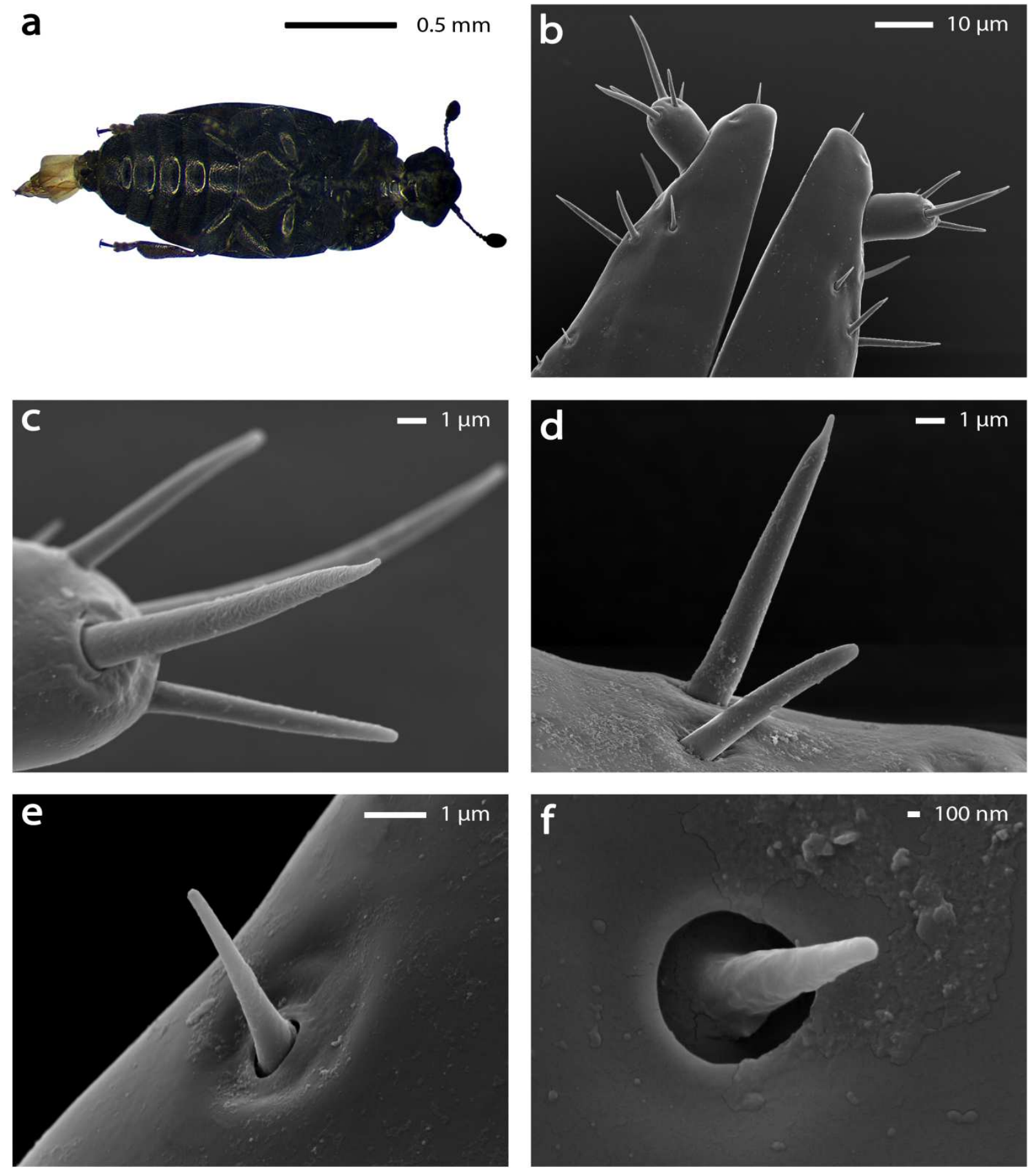

Fig. 1 Stereomicroscope observation: a - pollen beetle female (M. aeneus) with fully extruded ovipositor (x 4). SEM observation of the ovipositor: $\mathbf{b}$ - distal end of the ovipositor (gonostyloid) (x 1,400); c - Stylus borne by the gonostylus (x 7,000); d - trichoid sensilla (x 7,000); e - basiconic sensillum (x 15,000); f - basiconic sensillum (x 30,000) 


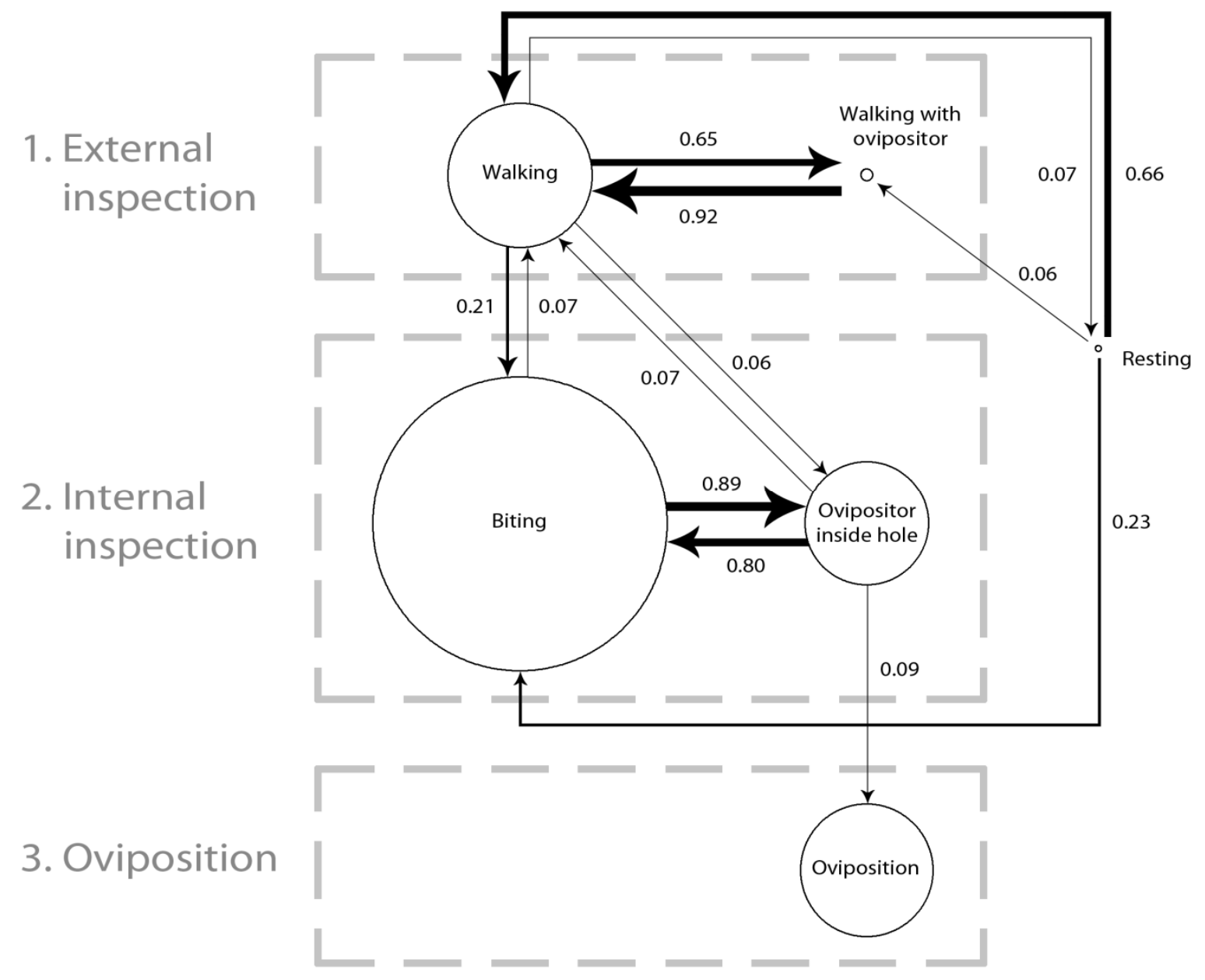

Fig. 2 Transitional diagram of behaviors of the oviposition sequence of the pollen beetle $(M$. aeneus) on oilseed rape (B. napus). Size of circles is proportional to the mean duration of the corresponding behavior. Size of arrows is proportional to the corresponding transition rate between the two linked behaviors. Transition rates $\geq 0.05$ are represented 

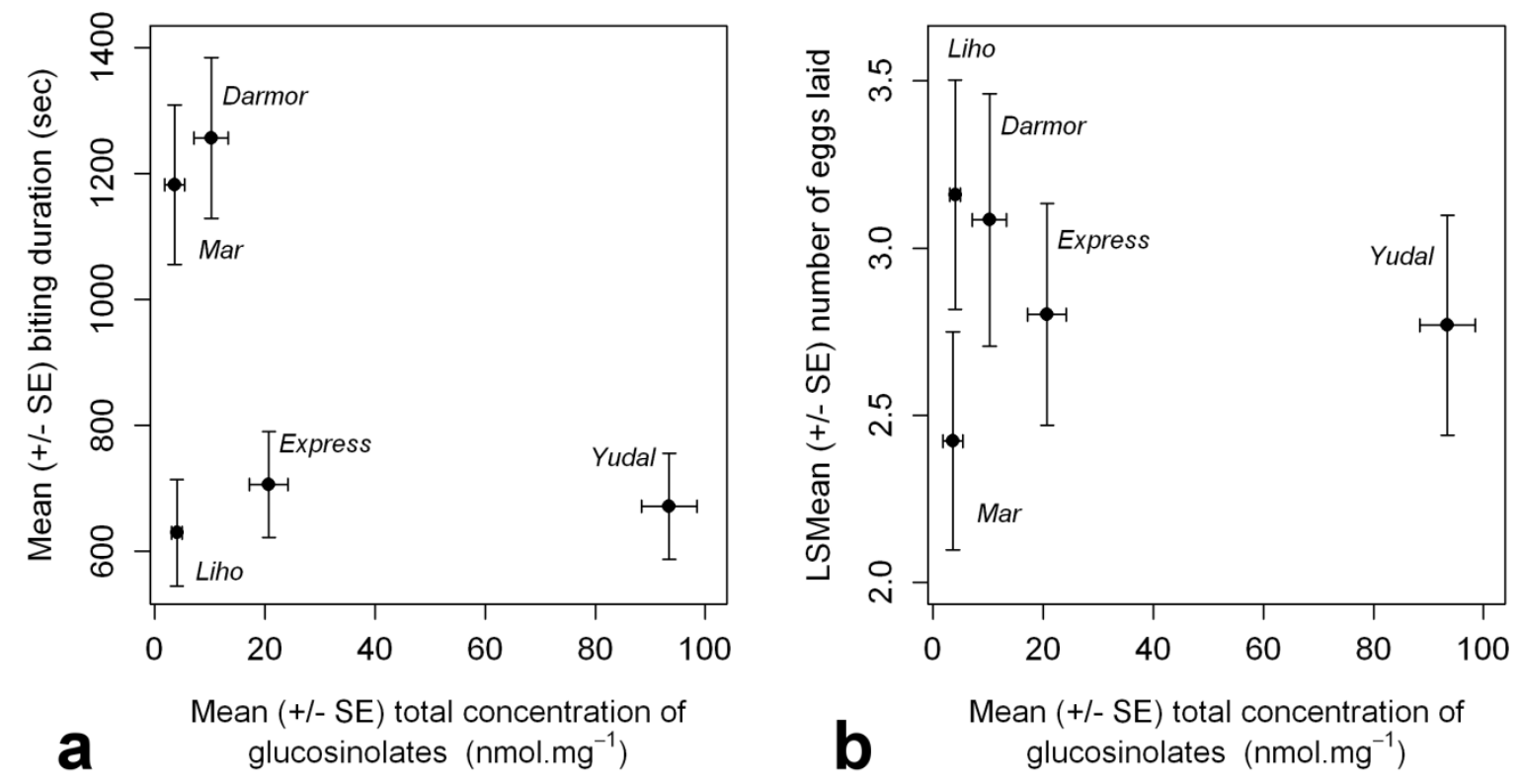

Fig. 3 Relationships between the mean total concentration of glucosinolates in the perianth of five oilseed rape (B. napus) genotypes and $\mathbf{a}$ - the mean biting duration of ovipositing pollen beetle (M. aeneus) females $\left(\mathrm{r}^{2}=0.18\right) ; \mathbf{b}$ - the mean number of eggs laid $\left(\mathrm{r}^{2}=0.03\right)$. Horizontal bars: $\mathrm{N}=4$ for 'Mar', $\mathrm{N}=5$ for other genotypes; vertical bars: $\mathrm{N}=25$ for 'Darmor' and 'Mar', 27 for 'Express' and 'Yudal', 29 for 'Liho'. Data on glucosinolate concentration come from Hervé et al. (2014a) 